\title{
Does the anthropometric profile influence infection morbidity after coronary artery bypass grafting?
}

\author{
Fernando Atik ${ }^{1}$, Helio Pegado ${ }^{1}$, Larissa de Brito ${ }^{2}$, Murilo Macedo $^{1}$, Edilson França Junior ${ }^{2}$, \\ Adhamys Dias ${ }^{2}$, Vitor Barzilai ${ }^{1}$, Renato Chaves ${ }^{1}$, Rodrigo Biondi ${ }^{1}$, Guilherme Monte ${ }^{1}$, and \\ Claudio da Cunha ${ }^{1}$ \\ ${ }^{1}$ Instituto de Cardiologia do Distrito Federal \\ ${ }^{2}$ Affiliation not available
}

December 19, 2020

\begin{abstract}
Background: Infection after cardiovascular surgery is multifactorial. We sought to determine whether the anthropometric profile influence the occurrence of infection after isolated coronary artery bypass grafting (CABG). Methods: Between January 2011 and June 2016, 1,777 consecutive adult patients were submitted to isolated coronary artery bypass grafting. Mean age was $61.7 \pm 9.8$ years and $1,193(67.1 \%)$ were males. Patients were divided into four groups according to the Body Mass Index (BMI) classification: underweight (BMI<18.5 kg/m2: N=17, 0.9\%), normal range (BMI $18.5-24.99 \mathrm{~kg} / \mathrm{m} 2: \mathrm{N}=522$, $29.4 \%$ ), overweight (BMI $25-29.99 \mathrm{~kg} / \mathrm{m} 2: \mathrm{N}=796,44.8 \%$ ) and obese (>30 kg/m2: N=430, 24.2\%). In-hospital outcomes were compared and independent predictors of infection were obtained through multiple Poisson regression with robust variation. Results: Independent predictors of any infection morbidity were female sex (RR 1.47, $\mathrm{P}=0.002$ ), age $>60$ years (RR 1.85, $\mathrm{P}<0.0001)$, cardiopulmonary bypass $>120$ minutes $(\mathrm{RR} 1.89, \mathrm{P}=0.0007)$, preoperative myocardial infarction $<30$ days $(\mathrm{RR}$ 1.37, $\mathrm{P}=0.01$ ), diabetes mellitus ( $\mathrm{RR} 1.59, \mathrm{P}=0.0003$ ), ejection fraction $<48 \%$ ( $\mathrm{RR} 2.12, \mathrm{P}<0.0001$ ) and blood transfusion (RR 1.55, $\mathrm{P}=0.0008$ ). Among other variables, obesity, as well as diabetes mellitus, were independent predictors of superficial and deep sternal wound infection. Conclusions: Other factors rather than the anthropometric profile are more important in determining the occurrence of any infection after CABG. However, surgical site infection has occurred more frequently in obese patients. Appropriate patient selection, control of modifiable factors and application of surgical bundles would minimize this important complication.
\end{abstract}

\section{Hosted file}

Anthropometry and cabg.pdf available at https://authorea.com/users/317830/articles/499651does-the-anthropometric-profile-influence-infection-morbidity-after-coronary-arterybypass-grafting 